\title{
Management of Change in the Changing School
}

\author{
Gabriela Diana NICULESCU ${ }^{1}$ \\ Florina Dorina VOICU ${ }^{2}$
}

\begin{abstract}
"Let us have the serenity of accepting what cannot be changed, the courage to change what can be changed, and especially the wisdom to make the difference between the two possibilities" Marc Aureliu. Since ancient times man as a social being has lived with other people. It goes without saying that human education has a paramount importance when it comes to its integration into society.

Reflecting, but also actively contributing to the society's evolution, the schools are in the permanent process of change. They both support and promote the change as a way for continuous modernization of economic and social life.

In order to qualify for quality education, there is a need for schools in order to have an appropriate change management in educational field that will lead to a quality education for the pupils and will increase their chances to become well integrated in the society.
\end{abstract}

Keywords: education and training, management, educational system, school

JEL classification: I21, I25, M12, M14

DOI: 10.24818/RMCI.2018.1.88

\section{Educational management}

Since ancient times man as a social being has lived with other people. It goes without saying that human education has a paramount importance when it comes to its integration into society.

Educational management in the form in which it exists today in Romania is a type of management that requires conceptual clarifications, having in mind that the very definition of this concept is not unitary at this time.

However, we can say that in the opinion of some specialists like Russu (1991) management designates the science of leadership of socio-economic organizations and their scientific leadership. It is attributing to it three meanings:

- a "science", an organized and coherent set of knowledge, concepts, principles, methods and techniques that systematically explains the phenomena and processes that take place in the leadership of organizations,

${ }^{1}$ Gabriela Diana NICULESCU, School no. 190, Bucharest

${ }^{2}$ Florina Dorina VOICU, School no. 190, Bucharest, Email: v_florina@ hotmail.com 
- an "art" that reflects the pragmatic aspects and which consists in the managerial skills of adapting to the realities of different situations, with good results, in terms of efficiency, scientific knowledge,"

- a specific "mood", reflected by a certain way of seeing, wanting, seeking and accepting progress. "

In fact, the educational manager is a person empowered to lead an organization such as the school in question, being endowed with qualities that enables him to achieve his goals by using diplomacy, empathy, leadership and guidance skills, all of which are summed up in the art which is able to guide the team to reach the proposed goals.

The educational manager must combine as an "artist" his leadership with the executive people, taking care to delegate tasks to his subordinates and being prepared to act in such a way that they can not refuse what he requests them to do. He must always keep in mind the training of his subordinates in order to successfully complete the manager's assignment. He has to be a visionary, but also a good commander, to control / evaluate without showing people around, to give personal positive examples, in short, to really get involved in school life.

At present, we cannot talk about an effective educational management without referring to the necessary informational system for daily communication both in school and especially outside it.

In order to communicate effectively, all participating actors need specialized training, continuous training, an appropriate material basis, the necessary funds for the acquisition of documents containing the information necessary for the good development of the educational process, as well as the tools through which to exchange information (see audio / video, PCs, faxes, xeroxes, SMART tables, etc.)

Managerial communication takes place between managers of educational institutions and within the same unit between the manager, other teachers and auxiliary staff.

Thus, the opinion of a specialist like Jinga (2001) is that "the purpose of managerial communication is very diverse and is done:

- to receive and transmit information

- to debate, clarify and solve a problem

- to make decisions for their explanation and implementation

- to transmit various tasks

- to motivate staff

- to guide the action

- for the evaluation of a person or activity, of a result

- to express opinions, feelings beliefs attitudes, etc .

British studies indicate that managers "spend" between $66 \%$ and $80 \%$ of their time for oral communication, while Americans claim it is $78 \%$, in accordance with Massie, Joseph, Douglas, (1985).

In the present society, the accelerated pace of the development of science and technology is also reflected in the field of education, and school is one of the 
essential institutions that by its very status promotes the evolution of Romanian education from the perspective of the concept of quality in education.

\section{Management of change in the educational field}

The schools are organizations that are subject to many pressures for change, pressures that come both from outside and inside of them. When we think to the factors that create a wide range of pressures on schools, we must pay attention to the different stakeholders that interact with the schools.

We have in mind external stakeholders as parents, local authorities, local community, employers, suppliers a.s.o. We also think to internal stakeholders as principals, pupils, professors, trade unions a.s.o.

It is pretty easy to understand that there a lot of pressures on schools to define a clear mission and to deliver the expected value for these stakeholders, approaches that involve permanent adaptation and planning for change.

The concern for education and its transformation is also visible to international level. The four common EU targets for 2020 that deals with education refer to:

- lifelong learning and development of mobility programs;

- improving the quality and efficiency of education and training;

- promoting equity, social cohesion and active citizenship;

- stimulating creativity and innovation, including entrepreneurship, at all levels of education and training.

These require the establishment of strategies within the institutional development in order to ensure the formation of active, competent citizens having the necessary critical thinking about the complexity of society.

The modernization of the educational system, the implementation of a new legislative system defined by the National Education Act are essential factors in identifying the applicable educational content at all levels regarding the institutional capacity, the educational offer, the structures and the decision makers.

In order to meet the current requirements, the school, as a social subsystem, must act in the name of valorizing exigencies that imply a certain structure and functionality of the didactic approach and to cope with on-going changes by focusing on the formative functions, by shaping the personality of a young person according to the requirements of his socio- professional integration.

School, as a fundamental element of education, has a strategic position in the progress of society, being influenced by the political, social and economic context. Current changes are permanent, they are often unpredictable, stressful, but quite necessary for the development of society (Smith, 2011).

The identification of the problems of the school as an institution, the complexity and the diversity of the activities that involve change are the basis of some development projects aimed at:

- continuous teacher training;

- ensuring school success for students capable of good performance; 
- integration of pupils with special educational needs and those with learning difficulties;

- developing school-family partnership

In the education system, any change must follow:

- human resource training

- acquiring new specific skills

- adapting learning to context

- promoting a system of values

- ensuring quality education

Change must be visible at the level of educational practice and it is a very complex phenomenon because it involves a number of factors that have an impact on the organizational component, within the framework of individual and group relationships (Revans, 1984).

The innovative changes of the educational system are the driving force and the development of the real power and the harmonization of the modern social trends.

The schools in Romania have to adapt their curricula to reflect the eight key competences as defined at EU that are considered to be necessary for personal development and social inclusion:

- communication in the mother tongue;

- communication in foreign languages;

- mathematical competence and basic competences in science and technology;

- digital competence;

- learning to learn;

- social and civic competences;

- sense of initiative and entrepreneurship;

- cultural awareness and expression

The National Curriculum has been changed to respond to the needs of learners in the twenty-first century. The national policies developed new strategies to improve the process of teaching and learning, focusing on specific skills to develop the digital and entrepreneurship competences (Rebernik, 2002).

A new project CRED - Open Curriculum Relevant Education for All - was launched by the Ministry of Education on 28th of March 2018. The project is tageted on:

- Teacher training in primary and secondary schools for developing the ability to design teaching-learning-evaluation centered on the new competences;

- Support for teachers to facilitate learning-based assessment in order to facilitate learning and to help each student to make progress in learning;

- Promote integrated (real life connections) and innovative approaches to the new curriculum

- Assigning complementary roles to teachers in the classroom, focusing on counseling, social mediation, facilitating learning in non-formal and informal contexts. 
The project is based on lifelong learning, teacher training needs aiming at adapting knowledge and teaching methods so that they can help prepare students for activities involving the use of new technologies and adapting to the challenges of a global society (Radu, 2009).

This strategic project proposes the curricular empowerment of a number of 55,000 primary and secondary school teachers to support the application of the new national curriculum and by doing that to increase the access of primary and secondary schools students to a quality educational act.

Thus, school must initiate relevant change processes to be able to ensure the implementation of educational policies and sustainable development goals.

In a constantly changing environment, the school manager must include in his programme activities designed to provide support, acceptance, approval for agreed transformations and changes (Wall, Walz, 2003).

The basis for change is strategic management, and the outcome of change management is determined by the abilities and qualities of all participants in the change implementation process.

In this context, the role of managers of school organizations in establishing and implementing modern, effective strategies for implementing change in the educational process is expected to be increased.

There are two kinds of changes that occur at the school level:

Changes required by circumstances;

Changes that are planned and adopted to increase the quality of the educational act.

Analyzing the following models: Kotter's Change Model,Adkar Mode,Deming Cycle we can conclude that at the level of the organization we have to realize:

- identifying change needs

- analysis of the internal environment and external factors that can ensure change

- formulation of strategies

- initiating a change process that ensure in schools reputation, quality, high performance

- implementing the strategy

- control of strategy implementation

- substantiating the directions to be followed

- analyzing the ways to solve the identified problem

Identifying and analyzing risk mitigation methods

It is clear that in order to minimize the impact on the organization by implementing change at any level, a complex process must be applied. This is related to the fact that the schools are complex organizations that have many stakeholders who are very interested about the functionality and results of such educational entities

92 Review of International Comparative Management

Volume 19, Issue 1, March 2018 


\section{Dealing with resistance to change}

As any process of change, the schools also face some reactions to change. Some of them are in favor of the introduced changes, others are of the nature to bring new questions about the opportunity or the way in which those changes are designed.

One of the most important resources in the school is represented by people and the managerial functions that refers to the human resources is a basic component in the curricular and institutional development of the school (Noye, 2002).

In all school organizations the processes of change that take place involve two stages. The first stage - the individual change - is usually the most difficult because it involves open information ensuring the transparency of the school's educational and decision-making policy and communication through numerous channels both inside and outside the system (Witzel, 2012).

Initiating, promoting, supporting change projects within an educational establishment involves the application of management methods and techniques, taking into account the specificities of the school and the local community:

- informing staff about the expected changes, arguing and presenting the advantages, limitations and risks;

- stimulating those who show interest in promoting new methods and teamwork;

- identification of interest groups

- Resistance to change, motivated by fear of the unknown, personal effort involving time and money, inertia and convenience are the risk factors in the process of individual change of the teacher and can have five sources:

- the selective perception of those aspects that fit the individual's philosophy of life;

- habit;

- dependence on others, it can result in resistance to change, until those who depend on it accept the change;

- fear of the unknown can generate anxiety and insecurity;

- economic reasons - direct or indirect revenue decline.

We can see that changes in the schools trigger both individual and organizational resistance to changes. These reactions are caused by objective and subjective reasons and the managers should pay attention to the wide range of forms that can dress these phenomena.

Resistance to the change forces the school's management to reconsider some characteristics of change, in terms of its depth, width and pace. Other important ways for preventing the exacerbation of resistance to change is to prepare a favourable climate for change and to foster the communication process, before, during and after the change. 
Each teacher should be aware of the importance of continuous training for the implementation of new teaching strategies, modern teaching-learning methodologies tailored to pupils' specificities, compatible with the requirements of the modern school (Năstase, et al, 2016). It is important that the innovators succeed in persuading those who follow them and who actually become opinion leaders.

By promoting positive examples within the school organization, by supporting and encouraging innovations in the process of formation of future generations, the director of a school becomes an important factor in ensuring adaptation of teachers' behavior in relation to the new foundations of organizational culture.

School leaders should monitor the impact of change on people and identify, in an open climate, the implementation issues, the resources and priorities of the school organization.

Human resources training should be based on the application of new methods and work techniques that enable didactic innovation and knowledge transfer to students so as to contribute to the development of critical thinking and to motivate them to actively participate in their own training.

An important role in the formation of the young people involved in the educational process is offered by the parents, who, if not informed about the mission of the school and if are not involved in knowing and capitalizing on the competences necessary for the empowerment of the future citizen, they risk to become an obstacle in process of change (Năstase, 2010).

Each parent must be aware of the fact that he or she is expected to participate in the formative process of the school and represents an important link in organizing and carrying out various educational actions.

The second stage - changing group relationships - which has as main objective the participation of all those involved in the life of the school, by the accumulation of efforts, in the design, development and evaluation of the organizational activities.

The dynamics of the current society require an opening to different alternatives in the formation of the competences of the secondary school students from the perspective of personal development (McDonald, Ross, 2000).

The Triad Master / Teacher - Student - Parent must work together in capitalizing on skills, personal capacities, moral dimensions in critical thinking development, so as to ensure an effective orientation in preparing for the future career.

The school as an educational medium must provide a modern basis of study through material changes - endowment with computer technology, new learning means appropriate to modern requirements, ergonomic furniture designed to allow both individual and team study.

The issues presented above are just some aspects of changes in the educational system that require the setting of strategic goals for the development of school as a learning organization (Green, 2007). 
A manager who wants to promote change at the level of the school unit must ensure redirection of human, material and financial resources so as to effectively contribute to school success and integrate the future citizen into a continually changing society, must have, according to Michel Fullan, a range of skills, such as :

- Understand the culture of the organization before attempting to change it through training;

- Valuates people with whom they work and promotes their professional development.

- Promotes what he thinks is valuable;

- Clearly expresses what he considers to be valid;

- Promotes collaboration with colleagues, not only co-opting them into various activities;

- Offers alternative actions;

- Uses bureaucratic means to facilitate participation and not to restrict it;

- Connects with the community environment.

The benefits of change management are associated with improved and efficient communication (Blix, et. Al, 1994). Better communication between primary education beneficiaries and school will lead to a better understanding of the needs and priorities of each of them and to the improvement of the quality of services offered to the trainees.

\section{Fostering the learning}

For centuries, very little attention was given to the "things of education". Education was envisioned primarily as people - teachers and learners. School buildings were incidental to the learning process. Wherever the Athenian teacher could conveniently hold a discussion with a small group of leaners that was where the school was. Education was primitive and uncomplicated in those days. Parents simply selected a teacher and sent only their boys to him. Oftentimes the school was nothing more than a teacher and a few students meeting on the open stairs of an ancient temple.

Recent advances in instructional methodology, educational psychology, and learning technology have stimulated the development of a wide variety of effective teaching aids. These new instructional tools have had a profound effect on modern educational thinking about the "things of education".

The concept of negotiated learning is not new. It is a revival of the learning methods familiarly known as "the contract method", "independent study", or "multioption instruction". The application of these concepts has much merit for those students who can profit from them. In general, their success depends upon the skill of the teacher in preparing and using well-conceived units of instruction and upon the initiative and resourcefulness of the student.

When both are present, the results from this approach to individualized instruction can be gratifying to both teacher and student. Negotiated learning 
allows the student to participate in shaping the learning experiences that he or she will undergo in achieving certain predetermined educational outcomes that may be in harmony with personal goals.

Change management must be based on flexibility, creativity, coherence, communication, motivation and the promotion of positive values and competencies that improve the performance of leadership in a modern school, deeply anchored in the reality of today's society.

\section{References}

1. Blix, A.G., Cruise, R.J., Mitchell, B.M., Blix, G.G., (1994). Occupational stress among university teachers, Journal of Educational Research, Vol. 36, No. 2, pp. $157-169$

2. European Agency for Development in Special Needs Education, (2006), Individual Transition Plans. Supporting the Move from School to Employment, European Agency for Development in Special Needs Education, Available at: https://www.european-agency.org/sites/default/files/individualtransitionplans_itp_en.pdf

3. Green M. (2007), Change Management Masterclass - A Step by Step Guide to Succesful Change Management, Kogan Page Limited, UK, p. 83

4. McDonald, Ross A. (2000), "Reframing Management Education: A Humanist Context for Teaching in Business and Society", Interchange, Vol. 41/4, pp. 385-401, Kluwer Academic Publishers, Netherland

5. Năstase, M., Dobrea, C., Valimareanu, (Mircioi) I., (2016), Promoting the Entrepreneurial Competencies for School Leadership Development, Review of International Comparative Management, Volume 17, Issue 1, March

6. Năstase, M., (2010). "Developing a Strategic Leaderhip Approach within the Organizations", Revista de Management Comparat Internaţional/Review of International Comparative Management, Bucureşti, Vol. 11, Issue 3, pp. 454-460.

7. Noye, D., (2002), Manager les performances. INSPE Consulting Editions

8. Radu, C., (2009), "The Influence of Leadership on Organization's Level of Competitiveness", Review of International Comparative Management, 10(5), 959-967

9. Rebernik, M.: "Business economics and entrepreneurship at the crossroads", Ekonomický casopis, Vol. 50, No. 3 (2002), pp. 471-488

10.Revans, R. (1984): “Action Learning: Are We Getting There?" Management Decision. Vol. 22, No. 1, pp. 45-53

11.Smith, I., (2011), "Organisational quality and organisational change", Library Management, Vol. 32, No. 1/2, pp. 111-128

12.Wall, J.E.; Walz, G.R. (2003). Measuring Up - Assessment Issues for Teachers, Counselors and Administrators, USA: NBCC

13.Witzel, M., (2012), A History of Management Thought, USA: Routledge

96 Review of International Comparative Management

Volume 19, Issue 1, March 2018 